\title{
Arousal decrease in Sleeping Beauty: \\ Audiences' neurophysiological correlates to watching a narrative dance performance of $2.5 \mathrm{hrs}$
}

\author{
Jola, C. ${ }^{1}$, Pollick, F. E. ${ }^{2}$, Grosbras, M. H. ${ }^{2}$ \\ ${ }^{1}$ Department of Psychology, University of Surrey, UK \\ ${ }^{2}$ Department of Psychology, University of Glasgow, UK
}

\begin{abstract}
Watching dance is a multisensory experience. In dance, movements are intertwined with music and/or sound, costumes, the narrative, light and stage design. Recent studies have found neuroscientific evidence that a dance audience processes visual and auditory information, while mentally simulating the movements. In other words, when spectators passively observe movements, their brain shows enhanced activity in areas that are also activated if they were executing the movements themselves.

This paper presents an unusual exemplar of a scientific study in which motor simulation was measured in an emotionally and kinaesthetically loaded real life setting. The study illustrates two main points: 1) real-life conditions matter because they change the results and call into question the validity of laboratory based experimental conditions for research which is making claims about lived experience outside the laboratory and 2) new hypotheses emerged about the effects that the length of time spent watching dance can have on cortical excitability and action observation responses.

The prevalent theory is that this mirroring process is automatic; however, it has been shown to increase with experience. It has been suggested that this mapping of observed movements onto one's own motor system helps in understanding the intention of the actions. A lot of effort is being put into gaining further insight into the role the mirror neuron system and motor simulation play in emotion regulation. One way of measuring motor simulation is by externally stimulating the motor cortex, which leads to small muscular responses that can be recorded in the form of motor evoked potentials (MEPs).
\end{abstract}


Changes in the size of MEPs are an indirect indicator of the level of motor corticospinal excitability.

Even though the equipment to measure cortical excitability is mobile, most neuroscientific studies have been conducted in a laboratory setting that has little in common with real life - in particular a dance audience's experience in the theatre. Here, we challenged this approach by measuring spectators' brain responses in the theatre while they were watching a dress rehearsal of a commercial production of Sleeping Beauty, lasting 2.5 hours, performed by the Scottish Ballet. However high the ecological validity of this study, it is a smallscale exploratory and rather playful approach producing data that is not eligible for statistical hypothesis testing. Nevertheless, we provide a specific example of how the factors 'time' and 'individuality' can affect scientific results in artistic settings if not acknowledged.

We observed that the brain responses of our spectators in terms of cortical excitability decreased with time, were strongly individual, and did not conform to prevalent movement simulation hypotheses. The finding that motor simulation is not automatic during movement observation, has important implications for the current understanding and research of mirror neuron activity. A contextual narrative may change the fronto-parietal mirror mechanism, which implies that previous findings based on controlled laboratory experiments could not automatically be transferred to real life. Interestingly though, the retrospectively-reported emotional responses of one spectator partly matched his objective measures of cortical excitability attained during the dance performance. Hence, qualitative responses may be linked to quantitative responses more than one would expect, while laboratory findings may not be considered as substitutes for real life situations as previously assumed. However, this study simply highlights these points for future investigations. The observation of a decrease of cortical excitability over time could either indicate subjects' adaptation to the procedure and the consequent effects of muscle relaxation; or changes in their emotional and cognitive engagement when watching dance. In either case, in line with research in dance studies that highlights the importance of time as a relevant factor in dance performance, this study shows that time is a relevant factor in measuring spectators' responses to watching dance. This will require future attention. 


\section{Introduction}

Watching a dance performance is a multisensory experience formed by the perception of a stream of audiovisual events. People are prepared to pay for this experience, quite often without knowing for certain whether they will like it or not. Dance can also be described as a complex socio-cultural practice that connects to a diverse range of motives, impulses and pleasures. Different types of theatre dances have emerged and made watching dance, too, a cultural practice with a diverse range of objectives, including exploration of movement, narrative, interpretation and spectacle (see Reason and Reynolds 2010; Reason 2010a). Here, we study how a dance audience watches a live dance performance on a neurophysiological and experiential level. For this, we measured cortical excitability while four spectators watched a dress rehearsal of the Sleeping Beauty and asked them at a later time point to rate their experiences of watching the dance retrospectively.

A large number of studies have measured human brain responses to action observation and found evidence for an increase in activity in particular areas such as the premotor and parietal cortices (see Pollick, Jola, Petrini, et al. 2011; Grosbras, Beaton, \& Eickhoff, 2010; Caspers, Zilles, Laird, \& Eickhoff, 2010). In general, activity was measured indirectly by using functional magnetic resonance imaging (fMRI) to measure enhanced levels of oxygenated blood flow as well as by using transcranial magnetic stimulation (TMS) to measure increased motor cortex excitability. In both types of measurements, enhanced activity while observing movements (increase in oxygenated blood levels and in cortical excitability, respectively) has been explained as a sign of motor simulation: watching somebody else performing an action induces internal 'rehearsal' of the action observed in the mind of the spectator in a muscle specific manner (Alaerts, Swinnen, \& Wenderoth, 
2009). When the spectators observe movements that they are experienced in performing themselves compared to other less familiar movements, cortical excitability is enhanced. For instance, experienced basketball players showed specific cortical excitability when watching basketball shoots (Aglioti, Cesari, Romani, \& Urgesi, 2008), which could be related to the fine-tuning of specific anticipatory resonance mechanisms that enable expert athletes to predict others' actions ahead of their realisation.

An increasing number of studies has shown a 'mirroring' of the observed movements in dance: increased activity was found when spectators observed movements that they were trained in performing as compared to observing unfamiliar movements (Calvo-Merino, Glaser, Grèzes, Passingham, \& Haggard, 2005; CalvoMerino, Glaser, \& Haggard, 2006; Calvo-Merino, Ehrenberg, Leung, \& Haggard, 2009; Cross, Hamilton, \& Grafton, 2006; Cross, Hamilton, Kraemer, Kelley, \& Grafton, 2009; Cross, Kraemer, Hamilton, Kelley, \& Grafton, 2009; Orgs, Dombrowski, Heil, \& Jansen-Osmann, 2008). Enhanced cortical excitability was also found while watching dance for spectators who were not trained but were visually familiar with the dance style they watched compared to novices (Jola, Abedian-Amiri, Kuppuswamy, Pollick, \& Grosbras, under review).

While such a complex aesthetically pleasing subject as dance has proved suitable to study basic neuroscientific questions, dance scholars and practitioners criticise the reductionist scientific approach to dance as well as querying the novelty and validity of the findings. One frequently hears comments along the lines of: "I have long experienced this! I often notice that I simulate movements that I watch; these data only show what we have known for a long time". However, we actually do not know how subjectively experienced sensations manifest themselves 
neurophysiologically. Neurophysiological data rarely relate to phenomenal experience. Though dance spectators may experience kinaesthetic and audio-visual sensations, their reports of these sensations are not necessarily reflected in neuronal evidences of their brains' sensorimotor processes (see Jola, Ehrenberg, \& Reynolds, 2011). Also, laboratory experiments are quite far from the real life situation of watching dance. Scientists remove any information from the stimuli that is not informative for the variables which they investigate experimentally. For instance, 'dance' stimuli are generally presented by a short video recording $(3 \mathrm{sec})$ of a moving body in front of a homogenous background in neutral clothing (see Calvo-Merino, 2010). In some cases they can be reduced to moving white dots on a black background, the so-called point-light displays (see Jola, et al., 2011). Hence, the subjective sensations that dancers and dance spectators experience in real life do not correspond to the sensations they have in scientifically controlled laboratory experiments. The question is: "Does it matter?" In other words, is the motor simulation mechanism different for different experiences? Is the action-observation mirroring theory drawn from data in strictly controlled experiments valid in complex real life environments?

We recognise both experience and complexity as relevant issues, and therefore have measured brain responses of audience members while they were watching a live dance performance and have also enquired into their qualitative experience retrospectively. Since we wanted to investigate the neurophysiological brain responses linked to dance spectators' experiential states, we matched the circumstances of the testing with the cultural practice of watching theatre dance as much as possible. Hence, four spectators watched a 2.5 hour long performance of Sleeping Beauty by the Scottish Ballet at the Theatre Royal in Glasgow while we 
measured their motor-cortical excitability. For ethical reasons of avoiding potential disturbance to paying spectators in a full performance, the testing was conducted during two dress rehearsals. Subsequent to the brain measures of motor simulation, we conducted qualitative semi-structured interviews with two of the participants that took place at a later date. The brain excitability was assessed indirectly by probing the motor cortex excitability with transcranial magnetic stimulation (TMS) while measuring motor-evoked potentials (Fadiga, Fogassi, Pavesi, \& Rizzolatti, 1995). By measuring the audience's responses in a real life setting our study respected all strands of dance performance, i.e. movements, costumes, presence, music, duration, narrative, and so on (see Preston-Dunlop \& Sanchez-Colberg, 2010), the only exception being that of the collective audience experience.

Sleeping Beauty is a ballet with an overture, a prologue, and three acts, first performed in 1890. It is based on a fairy tale first published in 1697 by Charles Perrault (Barchilon \& Pettit, 1960). The story begins with mortals mixing with the fairies of an enchanted forest in a magical kingdom. It includes the beautiful princess Aurora, her parents, a handsome Prince, and a number of fairies of which, the queen of the good fairies, Lilac and her twin sister Carabosse, the wicked fairy, are most central. The main character is Aurora, the Sleeping Beauty, who falls asleep after being pricked by a poisonous needle (in the Scottish Ballet version it is a cactus) and is then woken up by a prince from her long sleep with a tender kiss. The new version used here (see Figure 1) was choreographed by Ashley Page (Artistic Director of Scottish Ballet), performed by the Scottish Ballet company with the lavish sets and costumes of the international designer Antony McDonald, accompanied by 
Tchaikovsky's magnificent score, and performed live by the Scottish Ballet Orchestra (see Synopsis ${ }^{1}$, Images ${ }^{2}$, and Trailer $^{3}$ ).

Our working hypothesis was that different forms of salient emotional events in the performance evoke specific modulations of brain activity. This hypothesis was based on the understanding of dance as a socio-cultural activity that combines a number of motives (see first paragraph). Outside of the non-experimental setting of this research, the non-dance aspects would also include the whole social context into which watching dance also fits, such as anticipation and meeting and talking with friends - which, research suggests, plays a significant role in what audiences remember and value about watching dance (Reason 2010b). Hence, the movements themselves are just one aspect of how dance supports transference of meaning and emotion to the audience. Indeed, the function of the brain areas that were described as part of an 'action-observation network' has recently been discussed as being of relevance not only to internally 'mirroring' observed actions but also to decoding and producing emotional and social cues for successful interaction between individuals and groups (Keysers, \& Gazzola, 2006). Moreover, activity in the brain mirror system has been found to correlate with empathy (see Keysers, \& Gazzola, 2009). Hence, mirroring or simulating movements mentally may be linked to conscious 'monitoring' and thus 'experiencing' states of the observer. For example, humans are capable of identifying affective states from how people move (e.g. Pollick, Paterson, Bruderlin, \& Sanford, 2001); they can also observe social gestures (Knutson, Clellan, \& Grafman, 2008), facial emotion expressions (Enticott, Johnston, Herring, Hoy, Fitzgerald, 2008) or movements performed with specific emotional content modulates

\footnotetext{
${ }^{1} \mathrm{http}: / /$ www.scottishballet.co.uk/whats-on/current-productions/the-sleeping-beauty/synopsis.htm

${ }^{2} \mathrm{http}: / / \mathrm{www} . \mathrm{scottishballet.co.uk/whats-on/current-productions/the-sleeping-beauty/gallery.htm}$

${ }^{3} \mathrm{http}: / /$ www.scottishballet.co.uk/whats-on/current-productions/the-sleeping-beauty/film-clips.htm
} 
activity in the 'action-observation network' (Grosbras, \& Paus, 2006; Grèzes, Pichon, \& de Gelder, 2007).

However, no study has yet related the phenomenological experiences of spectators during a dance performance to their neurophysiological states and it is indeed not simple to do so. Hence, for the analysis we divided Sleeping Beauty into event types, based on previous extensive research into action observation, emotional perception, and gesture recognition as indicated above. We then compared the level of cortical excitability during these events with the audience members' post-event reflection on their level of engagement during different moments in the performance. Further, we divided the events the audience members watched at the moment of the TMS stimulation in terms of numbers of dancing performers on stage (solo, duo, group dances). An audience member sitting in the dress circle (like our participants) or even further away (as in many performances) may not actually see any facial emotional expressions. Hence, the motions or rhythms of the groups, visible from afar, may act as entrainment stimuli (Cummins, 2009). Finally, we investigated changes in the time-course. Motor-evoked potentials are known to have a high variability within and across subjects. However, to our knowledge, no other study has yet investigated how cortical excitability changes over such a long continuous timecourse.

\section{Methods}

\section{$\underline{\text { Subject Sample }}$}

We tested four healthy participants, Alexander, Oliver, Lily, and Jack (names have been changed), who were all right-handed with an average age of 30 years (SD = 6). They were all experienced dance spectators to different degrees: Alexander and 
Oliver watched on average about 8 performances a year, while the other two subjects had seen about two live dance performances on average over the last five years. All subjects except Jack knew the story of Sleeping Beauty quite well. For instance, they were surprised to see characters in Sleeping Beauty from other fairy tales, namely Snow White, Belle, Cinderella, and Red Riding Hood (which was specific to the interpretation of the Sleeping Beauty by the Scottish Ballet). Lily had seen several versions of the Sleeping Beauty, was familiar with the Disney cartoon and had seen a version of the ballet by the Russian Ballet in Australia. Oliver knew the story well but had never seen the Sleeping Beauty as a ballet before. This participant enjoyed the performance so much that he went to see the evening performance a couple of weeks later too - which is a good indicator that TMS does not hinder the enjoyment of watching. Importantly, none of our spectators had any formal or recreational dance training. The subjects were recruited with support from the Theatre Royal in Glasgow via questionnaires at previous dance performances at the Theatre Royal, as well as via email over the Watching Dance project list and the University staff and student list (Psychology Department). All spectators were asked post hoc to participate in a semistructured interview. Unfortunately only two of the four subjects (Lily and Oliver) were followed up. For these two participants, the quantitative data was compared with their qualitative reports.

\section{$\underline{\text { Procedure }}$}

The testing was approved by the local Ethics Committee and took place in the Theatre Royal in Glasgow while the Scottish Ballet had two consecutive dress rehearsals, each with a different cast, at $2.30 \mathrm{pm}$ and at $6 \mathrm{pm}$. The first rehearsal was interrupted due to a minor injury to one of the performers with a prop (drinking glass) and a dancer who had a fall in the middle of the first act. The EMG data for these 
events were removed from the EMG analysis. Both rehearsals were otherwise identical. The technical equipment to measure motor-cortical excitability consisted of a stimulator (Magstim 200, Dyfed, UK), a circular coil (90 mm circular), a electromyography (EMG) measurement pre-amplifier (CED 1902), and a number of electrodes ( $8 \mathrm{~mm}$ AG/AGCL sintered flat), see Figure 2 and 3. Two participants watched each performance. As motor cortex excitability measures could only be recorded from one participant at a time, the participants within each pair were tested in alternation. This procedure allowed us to test the maximal number of participants with only two rehearsal performances and the equipment at hand (see Table 1). The subjects were seated comfortably in front of the equipment next to each other in the third row of the upper circle (with two empty seats between them). Each participant was made familiar with the procedure. After they had given informed consent, the experimenters cleaned their skin at the selected electrode locations with alcohol and applied the electrodes with conductive paste. Participants were invited simply to enjoy the live performances they were going to watch. The TMS coils were held in place by two experimenters and TMS pulses were triggered for both participants using identical equipment and controlled by the same computer (via parallel port signal from ePrime). During each performance, each subject received at least eight bundles of 24 single TMS pulses (see Table 1 for individual measures), triggered randomly with an inter-pulse interval between 7 and 9 seconds, spread over the three acts of the performance. The average duration of each TMS bundle was 3 min 12 seconds, thus each subject was stimulated in total for an average of $25 \mathrm{~min}$ and 36 seconds over the 2.5hrs duration of the performance. The spectators were made aware at the start of each TMS bundle. To minimize disruption to watching the performance, no shams 
were applied. As a control, we measured a series of MEPs when the participants were at rest with their eyes closed after the performance.

\section{$\underline{\text { TMS and EMG recording }}$}

Single-TMS pulses were delivered according to standard procedure (Hess, Mills, \& Murray, 1987; see also Pascual-Leone, Davey, Rothwell, Wasserman, Puri, 2002; Wassermann, Epstein, \& Ziemann, 2008) through a circular coil with anticlockwise current flow, positioned over the vertex, which stimulates a large part of the upper limb representation in the motor cortex. The coil was held by one of the experimenters and its location was marked on the participants' skull. MEPs were recorded in three muscle groups, the right first dorsal interosseous (FDI), the right extensor carpi radialis (ECR), and the flexor in the forearm (see Figure 3). The response to TMS is dependent on a variety of factors that are not of experimental interest, such as skin conductance. TMS intensity was thus set at $120 \%$ of the individuals' resting motor threshold. The threshold was defined for each participant as the lowest TMS intensity that elicited MEPs in the FDI muscle larger than $50 \mu \mathrm{V}$ in 5 out of 10 stimulations. As expected, the MEP threshold was at different intensities for each participant, namely $44 \%$ (Oliver), $22 \%$ (RM), $60 \%$ (Jack), 48\% (Lily) with maximum of 2 Tesla at the coils' surface centre. EMG responses of the ECR, Flexor, and FDI were detected by electrodes in a standard belly-tendon montage. The ground electrode was placed at the inner side of the elbow, a neutral position as close as possible to the others. EMG signals were recorded in time-windows of $100 \mathrm{~ms}$ before and $400 \mathrm{~ms}$ after TMS with 1000 Voltage gain, $2.5 \mathrm{kHz}$ sampling rate, 20-1000 Hz filter, and Notch Filter. Recording and analysis of the EMG signals was done with specialised software (Signal 4.06). 


\section{$\underline{\text { Within-subjects Condition }}$}

Each participant watched passively the live performance of the Sleeping Beauty (see Figure 1). Each performance lasted 2.5 hours and was performed by professional dancers from the Scottish Ballet accompanied by a live orchestra. Prior to the testing, the experimenter identified different characteristics of the ballet which could affect cortex excitability over the time-course of the performance: 1) five types of events: emotional (such as the kiss scene), gestural (such as the drinking scene at Aurora's birthday party, or Lilac's gestural prophesies), physical (highly challenged dance movements in terms of their technicality and cardiovascular demand), effort (motion with high levels of effort, in particular those by the wicked fairy Carabosse), non-dance (such as discussions, interruptions, clearing the stage and the participants' rest with eyes closed); 2) the numbers of dancers: solo, duo and group performances; and 3) the time-course of the ballet: Prologue (the christening), Act 1 (the birthday party), 2 (the vision), and 3 (the wedding).

\section{$\underline{\text { Data Preparation }}$}

At least two of the three muscle groups (FDI, Flexor, or Extensor) had to show a clear distinguishable MEP (i.e., amplitudes between 1.5 and $0.005 \mathrm{mV}$ ), otherwise, trials were excluded from analysis. The sixty-five percent of all trials which satisfied this criterion were then rectified and the area under the curve computed for further analysis. The size of MEPs is very variable across and within individuals (PascualLeone, Davey, Rothwell, Wasserman, \& Puri, 2002). Therefore, to compare differences between events, number of dancers, and time-course, the area activity was averaged across each TMS bundle (see Table 1), and presented in percentage changes 
to the MEP amplitude sizes recorded during the rest condition (i.e, eyes closed) for each spectator.

\section{$\underline{\text { Data Analysis }}$}

Normally, as a first step, statistical tests would be computed to verify if the observations made here are generalisable over a wider population. One issue for neuropsychological analysis of our data is the low number of spectators, which reduces the power of our normally-applied statistical tests, and an understanding of the variance of a larger group of spectators would be required for most statistical tests (Bhattacharya \& Fao, 1976). Even 'bootstrapping', a new method that calculates confidence intervals for parameters by randomly re-assigning the observations when few data are available (Efron, 1979) does require a minimum number of samples that is above ours. With only four subjects, a large variability in EMG data, and an interest in comparison with qualitative data, we present the subjects' individual results (Figure 4) alongside a descriptive analysis. Only one statistical comparison with the data collected was feasible, by treating all TMS bundles as individual measures for each spectator and comparing them to zero. This procedure provides nine measures for each individual subject and makes it possible to test whether any subject shows significant changes from zero (see action observation in results section).

\section{Qualitative Interview}

The interviewer asked participants to remember and name events in the performance, to choose a term that best described how they responded to the performance (e.g. enjoyment, excitement), and then to indicate on a piece of paper the intensity of this experience for each remembered event (see Figure 5). Importantly, 
these data were collected after the performance event and describe the postperformance reflective activity of what the subjects remembered of the performance.

\section{Results}

Remarkably, as can be seen in Figure 4, the measurements showed that watching the ballet did not automatically increase cortical excitability compared to rest and cortical excitability seemed to decrease. These observations are described below under action observation and acts. However, there is no pattern visible that would indicate a relationship between cortical excitability and the factors events and number of dancers (see Figure 4 and Table 1).

\section{1) Action observation}

The data showed an unexpected characteristic across all observers, namely, no consistent increase in cortical excitability during action observation (the dance performance) compared to rest (eyes closed). Watching the ballet compared to eyes closed led to significant changes in cortical excitability in specific muscle groups: Oliver showed a significant decrease in cortical excitability in the Extensor, $\mathrm{t}(6)=$ 5.78, $p \leq 0.001$, while Jack showed a significant decrease in the Flexor, $\mathrm{t}(6)=-9.29, p$ $\leq 0.001$ as well as a significant increase in FDI, $\mathrm{t}(7)=3.02, p \leq 0.05$ [all one-samples 2-tailed $t$-test for each spectator and muscle group]. We did not see any specific relationship between the different events and MEPs that may have explained the large variability in cortical excitability while watching the Sleeping Beauty. 


\section{$\underline{\text { 2) Acts }}$}

A descriptive analysis of the observations showed that cortical excitability decreased over time. This is most obvious for Acts 1 and 2. Also noticeable are the high values in the Prologue and Act 1 across subjects. Cortical excitability for spectators Lily and Alexander reached their individual maximum within acts as well as across the acts at the very beginning of the performance. This reduction in cortical excitability across and within acts may indicate that motor simulation diminishes over time. One way to interpret this observation is that with time, spectators get emotionally and/or cognitively more involved in the narrative rather than the individual movements. We cannot however exclude the possibility with this one exploratory study that the reduction in cortical excitability is a coincidental finding specific for our particular testing, spectators, and dance performance.

Notably, with the exception of Act 3 in FDI (Oliver and Jack) and Act 3 in Extensor (Oliver) cortical excitability was continuously decreasing over time within all three acts, i.e. from the beginning to the end of an act. A decrease within the acts can be observed at least in half of the measurements: in the Prologue in 2 out of 2 cases, in Act 1 in 9 out of 11 cases, in Act 2 in 6 out of 9 cases and in Act 3 in 3 out of 6 cases. Also, there may be a trend for a decrease of cortical excitability over time across the three acts, i.e. from the beginning to the end of the ballet. This is in particular the case for Lily's FDI and Flexor; however, the other participants showed somewhat individual patterns of excitability during the ballet. This variability may be related to their engagement with the dance performance, their individual attention and/or their memory span. 


\section{3) Qualitative Reports and Individual Experience}

Some individual patterns can be noted: strikingly, Lily showed very high MEPs at the beginning of the Sleeping Beauty (they exceed the table and the percentage change is written on top of the bars). This spectator's percentage changes are much higher than normally reported in the literature. Electric interference in the theatre was immense, leading to high measurement artefacts and it may have distorted our MEP measures (despite similar conditions for all participants; we cannot exclude the possibility of specific variations for instance with changes in lighting). Further, Alexander's Flexor and Extensor responses are visibly similar across the ballet with the exception that in the Extensor in Act 1, the first measurement is lower than at rest. Oliver shows a similar response with Flexor being higher than at rest in Act 1 while the Extensor shows lower MEPs than rest. Interestingly, this was at the time when the dancer cut himself with a glass and the performance was interrupted.

While Oliver drew experienced modulations in engagement, Lily drew changes in enjoyment. Lily experienced the version of the Scottish Ballet as quite traditional in terms of the costumes (more ballet like). She remembered the end scene, the wedding, as being the most unusual of the whole performance, in particular because of seeing characters from other fairy tales appearing on stage. This could explain why her motor-cortex excitability is much enhanced in the beginning (where the physical movement phrases may have encouraged motor simulation) compared to the end (as she expressed surprise, cognitive aspects may have detracted from motor simulation). Her reflective reported levels of enjoyment were high during the Prologue for the time-point of the second TMS measure (when Carabosse enters the scene), which also showed high cortical excitability. This correspondence was not 
observed for Act 3, where she reported enhanced enjoyment, but the data did not show enhanced excitability. Similarly, Oliver showed a correspondence between cortical excitability in Act 2 and retrospectively reported levels of engagement (both showing a decreasing tendency) but the high reported levels of engagement in the Prologue and Act 1 are not reflected by cortical excitability which was rather low. Hence, there is no clear relationship between subjective reflective accounts and the immediately measured cortical excitability. Since qualitative responses do involve reflective components, they are probably not matching the immediate response to stimuli.

It is notable that the observations made for cortical excitability are very different from any of the qualitative reports. First, spectators clearly remembered the accidents that happened in the dress rehearsals. This shows clearly that what is of scientific interest does not always correspond to what we deem important to remember. Second, spectators remembered events independent of TMS application (more and other events). This shows that TMS did not disrupt the experience of watching dance memorably. However, as subjective experiences (remembered events) do not always match the time-points of measures in cortical excitability, they cannot be easily compared. Thus, we extracted only those qualitative responses that matched the time-period of TMS application (see Figure 6). Here, Oliver's levels of engagement seem to reflect cortical excitability somewhat (Figure 4), in particular the extensor. There is no such correspondence for the other spectator.

Qualitative research methods give emphasis to the way in which a story is told as a means of interpreting individual experiences. Lily mentioned the theatre helpers but not the accidents themselves. She refers to the size of the cactus (huge) and assigns an active role to it (cactus pricks Beauty). She also recollects the Prince who 
is hunting, the Prince who kisses Sleeping Beauty (active role of the male figure).

Lily described the fairies in the forest as 'pretty young girls'. The objects seem to be relevant to her too (the couch on which Aurora sleeps). Lily recollects the story with emphasis on objects and a male dominated perspective. Oliver does not mention dramatic events that imply relevant changes, he mentioned the cactus, and that the Princess falls asleep and the forest grows, but he does not say why. He also does not mention the wedding (which he describes instead as the 'finale bit') and describes as 'mythical fairytale women' the figures Lily refers to as 'pretty young girls' in the forest. Considering these very individual narratives, one may wonder if the events of the theatre may need to be categorised differently for each individual.

\section{Discussion}

The combination of the movements, music, costumes, light, and dramaturgy of a dance performance make it a unique multisensory experience for the spectator. We investigated whether motor-cortical excitability, an indicator of 'mirroring' and/or of mentally simulating observed movements as shown in previous studies, is qualitatively modulated by the content of specific events, numbers of dancers moving on stage, and the time-course of the performance when watching a live dance. As the number of neuroscientific-artistic studies in action observation is increasing, we believe it is relevant to explore existing theories such as the functional relevance of the mirror neuron network with ecologically valid studies even though they come at high costs (from a scientific perspective): a factorial design that would allow systematic statistical analysis is not possible for a study like this. Nevertheless, we 
were able to pinpoint hugely important factors for future studies conducting action observation research in dance, as discussed below.

\section{$\underline{\text { Time-course }}$}

Of the factors explored, time-course could be seen to have an effect across four spectators with decreasing excitability within and across the three acts of the Sleeping Beauty.

As stated earlier, motor-evoked potentials are an indirect measure of cortical excitability and can be influenced by many physiological parameters, including arousal and attention (see Schmidt et al., 2009). Subjects may have become more relaxed as they adapted to the TMS and the novelty of the experimental procedure and/or they may simply have got tired, or become customised to the dance style. We propose, however, that the observed decrease may have different causes altogether. First and foremost, even though the measure of motor simulation by means of MEP modulation includes more than just the brain (it comprises the pathway from the brain to the muscle), there is converging evidence that the facilitating effect of action observation originates at a cortical rather than at the spinal or muscular level (Baldissera, Cavallari, Craighero, \& Fadiga, 2001, Strafella \& Paus, 2000, Siebner \& Zimmerman, 2007). Also, the commonly observed decrease of MEP amplitudes over time has been attributed to cortical states (Schmidt et al. 2009). Schmidt et al. showed that until about 20 stimulations, the MEPs are not normally distributed, due to an initial transient-state and thus suggest ignoring early trials and using only later ones, that are steady. The decrease observed in our study is unlikely to show a transition between initial and steady states as we did not stimulate continuously. Each spectator was stimulated 24 times with long rest periods in-between, allowing cortical 
excitability to go back to baseline, and transient effects should be expressed in a similar way in all bundles of TMS. Also, contrary predictions of cortical excitability modulation over time exist but none of them applies to our setting. First, a general increase in motor cortex excitability is deemed to be a sign of cortical synaptic plasticity, which for example can be induced by training. Hence, one would expect that while spectators become more familiar with the ballet over time, they would engage more with the dance movements and thus show increased rather than decreased cortical excitability. Secondly, a decrease in motor-cortex excitability has been discussed as an effect of fatigue of the central nervous system or cortical neuronal reorganization taking place after exercise. Bonato, Zanette, Fiaschi, \& Rossini (2002) found evidence that MEP modulation measured after execution over long periods of up to 30 minutes reflects plastic neuronal reorganisation rather than fatigue. Also, McDonnell and Ridding (2006) found that cortex excitability is suppressed even up until 10 minutes after hand movements. Hence, one would expect that the longer spectators remained seated, the less strong the suppression is, with increasing MEPs. In contrast, we found a reduction of MEPs the longer the spectators remained without moving. To summarise, neither cortical states, nor familiarity with the stimuli nor fatigue can explain the observed decrease. The finding that cortex excitability is modified over time for all three acts was even more surprising since the intervals of the dress rehearsals were only for the duration of changes in stage settings lasting 2 min, 4 min, 10 minutes and 22 minutes, and thus shorter than most intervals between TMS. This again argues against changes in cortical states as the reason for the observed decrease in excitability over time.

Hence, we claim that spectators simulate the movements less, the longer they engage emotionally and cognitively with the story-line of the ballet. This is 
contradicting previous assumptions on the mirror neuron system as a direct and automatic function that is not competing with other processes. Potentially, a spectator's kinaesthetic experience could be triggered directly by the movements through motor simulation as well as in a roundabout way by engaging in the storyline. While kinaesthesia could be experienced in either case, enhanced cortical excitability is only evident when there is a mapping of the observed movements. Importantly, these assumptions would predict a big difference of motor simulation for narrative and non-narrative dance. Reduced cortical excitability may not indicate a lack of mental involvement in social and/or physical stimuli but another form of participation. In dance and theatre it is well known that time is of great importance. It is the dramaturgy of a work that ensures that the performance develops the storyline in narrative dance forms in a way that engages the observer. Dance scholars have discussed time further with regard to the movement qualities of the performer (e.g. dynamics of a movement taking place in time), changes in the performer as he/she matures (e.g. Jackson, submitted), the representation of the passage of time in particular in the Sleeping Beauty (e.g. Hammond, 2005), and in improvisation with music for both the spectator and the performer (e.g. Lycouris, 2008). Only with the passage of time can the genre of the dance (from conceptual to narrative dance) be defined and the spectators' attention be manipulated. However, this is the first study demonstrating that the neurophyiological response to watching dance changes with time.

The involvement of the spectators - and maybe the occurrence of motor imagery (Fadiga, Buccino, Craighero, Fogassi, Gallese, Pavesi, 1999) - is an important aspect of the degree to which motor simulation can be identified via cortical excitability. The aim of many dances is to allow the spectators to immerse fully. On 
the one hand, a spectator may embody the characters on stage to such an extent that there is no sense of "self" (i.e., identification). On the other hand, a spectator can subjugate a story to his own liking, the "lived narrative" (i.e., projection). Identification and projection both give the spectator an internal "first-person" comprehension of the observed actions; but are, however, not discussed as the principal functions of mirror neuron activity. In other words, observing actions in an engaged manner may not always automatically lead to motor simulation manifested in enhanced cortical excitability.

Perceiving art is recognised as a potentially active and dynamic experience, involving our cognitive capacities. "Aesthetic experience is not given once and for all. It changes through time and (hopefully) gets better and better through its very exercise: the more we look at art, the more perceptive of art we get" (Reference to Goodman, 1976 in Reboul, 1995). Clearly, time plays an important role in the appreciation of dance as a performative art, and the initiation of emotional sensations in the spectator by the performer is important.

\section{$\underline{\text { Null-findings }}$}

Contrary to our expectations, we did not find consistent effects of numbers of dancers or type of events and cortical excitability was not automatically increased in all instances during the performance (action observation). The former may be due to an unbalanced design. The latter is however contrary to what common theories on action observation would predict, namely that cortical excitability is automatic and consistently increases during action observation compared to rest, and our findings are thus unexpected. What may be the reason for the null-effect and its implications? 
The emphasis in most studies is on showing evidence for mirror neuron activity in action observation and other types of stimuli rather than on rejecting the mirror neuron theory. Hence, much less is known about the circumstances when there is no mirror neuron activity despite action observation than when there is. In our study, participants sat quite far away from the stage. Wildschut (2010) found that dance spectators who sit further away are less emotionally and kinaesthetically absorbed in the movements they observe. However, the motor system is involved in mirroring observed actions even when the body is only sparsely (Alaerts, Van Aggelpoel, Swinnen, \& Wenderoth, 2009) or not at all visible, as in point-light displays (see Jola et al., 2011). Also, the distance between spectators and stage was consistent throughout out the experiment, and thus cannot explain the changes we found in MEPs during action observation. Further, motor cortical excitability can be modified by factors other than movements. For instance, the pleasantness of stimuli has also been shown to change cortical excitability (Coelho, Lipp, Marinovic, Wallis, \& Riek, 2010). Emotion in dance can be recognised by adults as well as children from the age of 4 (Largerlof \& Djerfa, 2009) and is one of the motives for watching dance. Expressive nuances, feelings and communicative intent of dance movements have been shown to affect cognitive processes not found in other movement based tasks (Stevens \& McKechnie, 2005). Hence, our classification of events into physical, emotional, gestural, and effort may not have been specific enough to show the influence of the emotional content of observed actions on motor simulation.

The findings with regard to the "what" and "how" of observed actions are however divergent. Donne, Enticott, Rinehart, and Fitzgerald (2010) observed that cortical excitability was enhanced during the perception of goal-directed behaviour and actions within a social context; however, the responses were not any stronger to 
either goal directed stimuli or to activities within a social context. By contrast, Hesse, Sparing and Fink (2008) found that when spectators set their attention to how a movement was performed rather than the outcome of the movement, areas of the mirror neuron system were significantly more activated and cortical excitability showed a muscle-specific increase. These findings support our previous assumption, namely that with time, our spectators attend more to the narrative of the dance performance and the movements per se become less relevant.

\section{Learning Process}

One principle of scientific investigation is reliability. This can be achieved by obtaining reproducible observable, empirical, measurable evidence according to specific rules of scientific reasoning. Laboratory experiments fit the demand for replication because the conditions and procedures are controlled and reduced so that exact duplication of experiments is possible - whereas testing in a real-life scenario, we experienced a number of complications, one of which is unpredictability. For instance, when one of the principal dancers fell, the rehearsal had to be stopped and the stage cleaned. Similarly, it becomes evident that any factor tested is artificial and not equally balanced in real life. Adjusting the testing in an ad hoc manner can be strenuous and increase the chances of mistakes and technical faults. In the laboratory, testing can be prepared, repeated, and delayed. The design is created to test a specific hypothesis. In the theatre, the performance is created irrespective of any balanced design, and the scientist has to adjust to any occurring event. As for the testing procedure, with such little power and control, training and rehearsal for the scientist is just as important as for the dancers. The researchers have to know the performance and procedures inside-out in order to conduct the testing in the dark, with suitable 
subjects, and instant adjustments. As for the results, it becomes evident that moving the neuroscientific experiment into a real-life environment brings to the surface all the factors that are known to create divergence between qualitative and quantitative research: the data are unlikely to be reliable (no single performance is the same), and the findings cannot be generalised (individuality of the responses). For example, considering the importance of time as we have just found in our study, no experiment can be exactly the same, since time has intervened between the primary and secondary testing. This fact is well acknowledged in other disciplines, such as anthropology. Further, narrative methods do recognize aspects of time. The question here is how a contemporary form of studying the human brain could incorporate such ideas.

\section{$\underline{\text { Summary }}$}

This paper describes the first TMS study of a real life event. As stated in the introduction, watching dance has a diverse range of objectives, including exploration of movement, narrative, interpretation and spectacle. Our data showed evidence that time is a relevant factor in the cultural practice of watching dance. Within the timecourse response that was common for all four subjects tested, we also found that the emotional response to watching dance was an individual one. Most surprisingly, we found no consistent evidence for motor simulation during extended action observation in the theatre. This study thus provides a discussion of potential problems for the movement simulation hypothesis. Are mirror neurons only measurable in the controlled situation of the experimental lab? The human mirror neuron system still needs to be validated in complex embedded real-life environments.

With only four subjects, our small sample is non-representative. However, we showed that it is possible to gain neurophysiological observations in the real world, 
with our results giving relevant insights into the neurophysiological processes that a dance spectator may experience. When neuroscientific experiments refer to real-life events, it is crucial that the stimuli actually correspond to the experiences in real life. Dance is a universal and diverse cultural practice with specific descriptive factors. We have shown here, that for the spectator, duration matters. In other words, we argue that experiments investigating motor simulation by means of TMS should carefully consider the factor of time as the neurophysiological observations seem to be dependent on the time course of the story (macro level) rather than movements (micro level). Hence, when assessing the experience of watching dance, the dance movements cannot be reduced to micro-levels. This is a very important message as it is common practice to investigate the human mirror neuron system with recordings of very short movements of about 3 seconds that are not continuous. At least in the case of measuring brain responses to watching dance, the factors that determine 'dance' as a cultural practice should remain consistent when using 'dance' as the stimulus and/or the reference in experimental studies. Neuroscientific models are based on statistical inferences on data gained in controlled experimental settings, mostly conducted in the lab, and the stimuli used are generally of a maximum duration of three seconds. This is inevitably something very different from a real life performance, with the result that the object of a scientific enquiry into spectators' response to watching 'dance' can become unrecognisable as dance. Thus, considering that we want to study the sociocultural experience of a group of people, the time is ripe for considering approaches with high ecological validity. This study demonstrated that we can run scientific experiments in the real world. In other words, our subjects were situated in the real world, becoming spectators of an environment while their experiences were measured by experimental standards. This is an innovative path that we hope many more 
scientists will take in future. This will not only increase our understanding of the human cognitive-emotional processes but may also be a solution for a more replicable anthropological inspired neurophysiology.

\section{Acknowledgments}

This research was funded by the AHRC (Arts and Humanities Research Council) through Watching Dance: Kinesthetic Empathy (www.watchingdance.org). Support from colleagues on the Watching Dance project is acknowledged (for this paper in particular Dr Matthew Reason who conducted the qualitative interviews), although the views expressed here do not necessarily reflect those of the whole project team. We would like to thank Scottish Ballet, especially Charlotte Gross. We are grateful to Seon Hee Jang for questions regarding the dance, to Jennifer Jackson for fruitful discussions based on an earlier version of the manuscript and to Jason Lauder for his technical support, to all members of staff who helped with carrying the equipment, to the dancers, our subjects, and the reviewers' helpful comments. 


\section{Figure Legends}

Figure 1. Still from the Sleeping Beauty live performance of Scottish Ballet. Paul Liburd as the Romanian Prince, Christopher Harrison as the Austrian Prince, Claire Robertson as Aurora, Tama Barry as the Russian Prince and Gregory Dean as the French Prince in Ashley Page's The Sleeping Beauty. Photograph by Andrew Ross.

Figure 2. Technical equipment and testing environment. Shows the experimenter holding the circular headcoil (that applies the magnetic stimulation), the spectator (sitting), two laptops (experimental program and data saving), magnet stimulator and amplifier.

Figure 3. Electrodes application. Thenar (not analysed due to technical error), FDI, Flexor, Extensor.

Figure 4: Changes in motor-cortical excitability of four spectators (Alexander, Oliver, Lily, Jack) by means of motor evoked potentials (MEPs) evoked by transcranial magnetic stimulation (TMS) of three muscle groups FDI (upper row), Flexor (middle row), and Extensor (lower row). Each act is presented in a different colour with decreasing intensity for the time from the start of the act. y-axis: average MEP area as percentage changes to the rest condition. $\mathrm{x}$-axis: TMS bundles in different acts for different events. Flexor in Act 1 for Alexander is missing due technical error. For demonstration purposes, values higher than $200 \%$ are indicated by the absolute value on top of the column.

Figure 5: Qualitative responses of Lily and Oliver. Notably, the structure of the acts was remembered incorrectly by both spectators. Direct comparison of qualitative responses with TMS trigger is not possible as more events were remembered retrospectively than TMS triggers were applied.

Figure 6: Qualitative responses of Lily and Oliver for those events that lay within the frames of TMS application. 
Table 1. Overview of the time course of the TMS stimulation for each spectator. $\mathrm{T}=$ Timepoint from the start of the performance in the format of hours:minutes:seconds. T may not correspond between the two rehearsals as the break-time varied, eg. the $1^{\text {st }}$ break in the afternoon was 9 min, in the Evening 22 min. $\mathrm{D}=$ Number of Dancers.

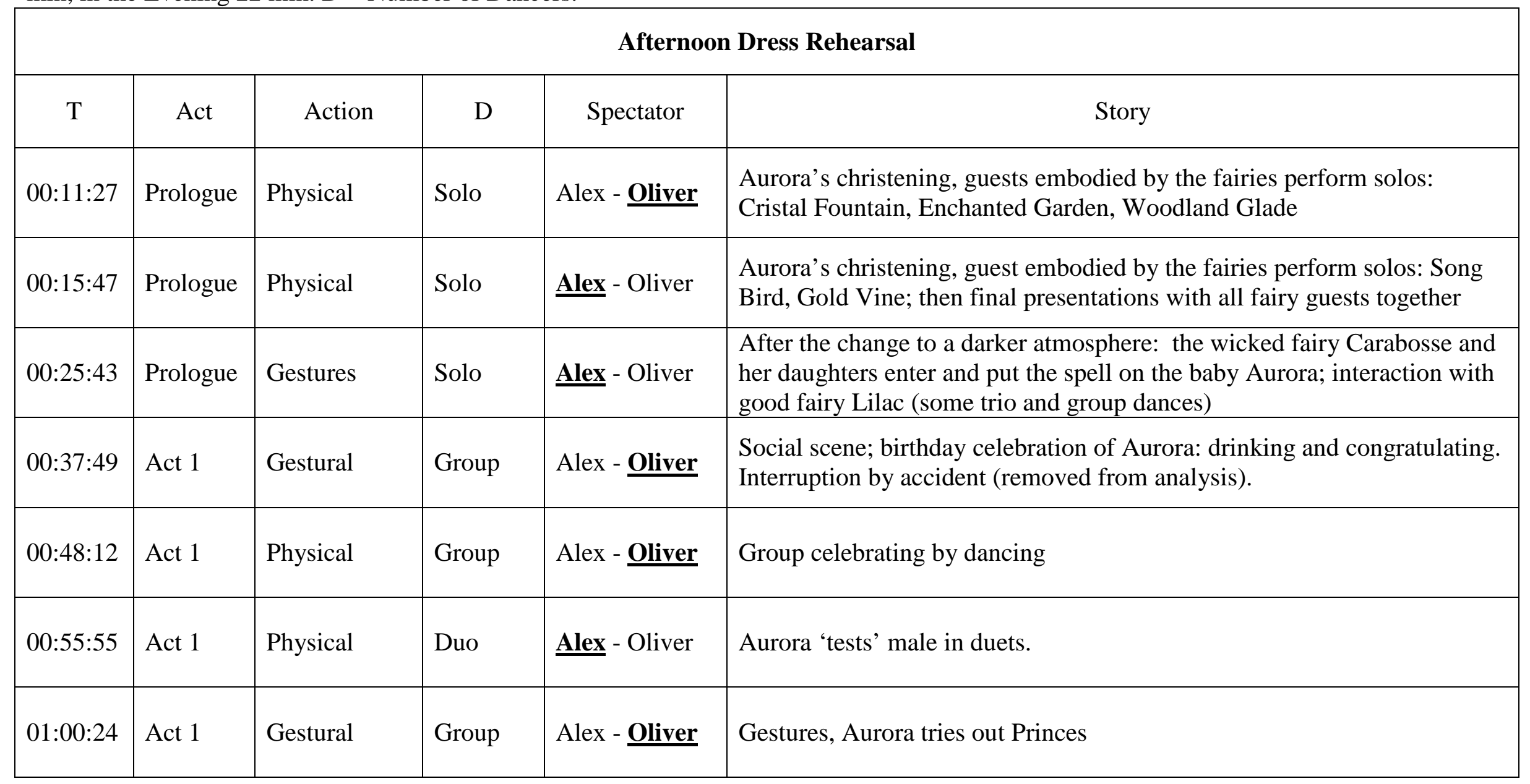




\begin{tabular}{|c|c|c|c|c|c|}
\hline $01: 26: 20$ & Act 2 & Effort & Group & $\underline{\text { Alex }}$ - Oliver & Carabosse and her daughters enter the forest \\
\hline $01: 36: 17$ & Act 2 & Emotional & Duo & Alex - $\underline{\text { Oliver }}$ & Prince awakens Aurora from sleep by a tender kiss \\
\hline $01: 52: 24$ & Act 3 & Physical & Solo & $\underline{\text { Alex }}$ - Oliver & $\begin{array}{l}\text { Wedding scene, Wedding guests are enjoying themselves dancing: Prince, } \\
\text { French Prince and Belle }\end{array}$ \\
\hline 02:00:54 & Act 3 & Physical & Duo & Alex - $\underline{\text { Oliver }}$ & Wedding scene, celebratory dances: Lady Bluebird with Bluebird \\
\hline 02:11:44 & Act 3 & Physical & Solo & $\underline{\text { Alex }}$ - Oliver & Wedding party, continues, Aurora \\
\hline 02:21:01 & Rest & Eyes-closed & $\begin{array}{l}\text { Eyes } \\
\text { closed }\end{array}$ & $\underline{\text { Alex }}$ - Oliver & Eyes closed, Cleaning Stage \\
\hline
\end{tabular}




\begin{tabular}{|l|l|l|l|l|l|}
\hline 02:27:08 & Rest & Eyes-closed & $\begin{array}{l}\text { Eyes } \\
\text { closed }\end{array}$ & Alex - Oliver & Eyes closed, Cleaning Stage \\
\hline
\end{tabular}

\begin{tabular}{|c|c|c|c|c|c|}
\hline $\mathrm{T}$ & Act & Action & $\begin{array}{c}\mathrm{N} \text { of } \\
\text { Dancers }\end{array}$ & Spectator & Story \\
\hline $00: 25: 33$ & $\begin{array}{l}\text { Pro- } \\
\text { logue }\end{array}$ & Gestural & Solo & 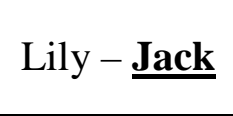 & $\begin{array}{l}\text { Aurora's christening, Lilac fairy explains the spell on aurora, that she will } \\
\text { not die }\end{array}$ \\
\hline $00: 55: 17$ & Act 1 & Physical & Group & Lily - $\underline{\text { Jack }}$ & Dancing at Aurora's birthday party, duos and group dances (only men) \\
\hline 00:59:13 & Act 1 & Physical & $\begin{array}{c}\text { Solo \& } \\
\text { Duo }\end{array}$ & $\underline{\text { Lily }}$ - Jack & Aurora solo, gestures, Aurora tires out Princes \\
\hline 01:26:03 & Act 2 & Physical & Solo & Lily $-\underline{\text { Jack }}$ & Male gun solo, fairy joins, bluebird solo and all fairies \\
\hline
\end{tabular}




\begin{tabular}{|c|c|c|c|c|c|}
\hline $01: 33: 38$ & Act 2 & Effort & Group & $\underline{\text { Lily }}-$ Jack & $\begin{array}{l}\text { Carabosse and her daughters in the forest, lilac fairy with gun man, green } \\
\text { man, duo man for a short period }\end{array}$ \\
\hline 01:42:00 & Act 2 & Gestural & Group & Lily $-\underline{\text { Jack }}$ & $\begin{array}{l}\text { Short TMS forest, curtain falls ( } 1 \text { trigger nothing), Carabosse enters again, } \\
\text { Aurora sleeping in the background, they all enter her room and she is } \\
\text { awakened by the Prince's kiss }\end{array}$ \\
\hline $01: 45: 52$ & Act 2 & Emotional & Duo & Lily - $\underline{\text { Jack }}$ & Duo prince and Aurora \\
\hline $01: 55: 27$ & Act 3 & Physical & Group & Lily - $\underline{\text { Jack }}$ & Wedding, Reception scene \\
\hline $01: 59: 30$ & Act 3 & Physical & Solo & $\underline{\text { Lily }}$ - Jack & Wedding Reception Scene, Prince, French Prince and Belle \\
\hline 02:07:54 & Act 3 & Physical & Duo & Lily - $\underline{\text { Jack }}$ & Lady Bluebird with Bluebird \\
\hline 02:31:19 & Rest & Eyes-open & $\begin{array}{l}\text { Eyes } \\
\text { open }\end{array}$ & $\underline{\text { Lily }}$ - Jack & Eyes open cleaning stage \\
\hline
\end{tabular}




\section{References}

Aglioti, S. M., Cesari, P., Romani, M., \& Urgesi, C. (2008). Action anticipation and motor resonance in elite basketball players. Nature Neuroscience, 11, 1109-1116.

Alaerts, K., Swinnen, S. P., \& Wenderoth, N. (2009). Is the human primary motor cortex activated by muscular or direction-dependent feature of observed movements? Cortex, 45, $1148-1155$.

Alaerts, K., Van Aggelpoel, T., Swinnen, S. P., \& Wenderoth, N. (2009). Observing shadow motions: resonant activity within the observer's motor system? Neuroscience Letters, 461(3), 240 - 244.

Barchilon, J., \& Pettit, H. (eds., 1960). The authentic mother goose fairy tales and nursery rhymes. Alan Swallow: Denver, Colorado.

Bonato, C., Zanette, G., Fiaschi, A., \& Rossini, P. M. (2002). Activity-dependent modulation of synaptic transmission in the intact human motor cortex revealed with transcranial magnetic stimulation. Cerebral Cortex, 12(10), 1057 - 1062.

Baldissera, F., Cavallari, P., Craighero, L., \& Fadiga, L., (2001). Modulation of spinal excitability during observation of hand actions in humans. European Journal of Neuroscience, 13, 190194.

Caspers, S., Zilles, K., Laird, A. R., \& Eickhoff, S. B. (2010). ALE meta-analysis of action observation and imitation in the human brain. Neuroimage, 50(3), $1148-1167$.

Calvo-Merino, B., Ehrenberg, S., Leung, D., \& Haggard, P. (2009). Experts see it all: configural effects in action observation. Psychological Research, 74(4), $400-406$.

Calvo-Merino, B., Grèzes, J., Glaser, D. E., Passingham, R. E., \& Haggard, P. (2006). Seeing or doing? Influence of visual and motor familiarity in action observation. Curr Biol, 16, $1905-1910$.

Calvo-Merino, B., Glaser, D. E., Grèzes, J., Passingham, R. E., \& Haggard, P. (2005). Action observation and acquired motor skills: an FMRI study with expert dancers. Cereb Cortex, 15, $1243-1249$.

Calvo-Merino, B. (2010). Neural mechanisms for seeing dance. In B. Bläsing, M. Puttke, \& Th. Schack (Eds.), The neurocognition of dance. Mind, movement and motor skills (pp. 153-176). Psychology Press: Hove, UK.

Cross, E. S., Hamilton, A. F., \& Grafton, S. T. (2006). Building a motor simulation de novo: observation of dance by dancers. Neuroimage, 31, $1257-1267$.

Cross, E. S., Hamilton, A. F., Kraemer, D. J. M., Kelley, W. M., \& Grafton, S. T. (2009). Dissociable substrates for body motion and physical experience in the human action observation network. European Journal of Neuroscience, 30, 1383 - 1392. 
Cross, E. S., Kraemer, D. J. M., Hamilton, A. F., Kelley, W. M., \& Grafton, S. T. (2009). Sensitivity of the action observation network to physical and observational learning. Cerebral Cortex, 19, $315-326$.

Coelho, C. M., Lipp, O. V., Marinovic, W., Wallis, G., \& Riek, S. (2010). Increased corticospinal excitability induced by unpleasant visual stimuli. Neuroscience Letters, 481, 135 - 138.

Cummins, F. (2009). Rhythm as an affordance for the entrainment of movement. Phonetica, 66(1-2), $15-28$

Donne, C. M., Enticott, P. G., Rinehart, N. J., Fitzgerald, P. B. (2010). A transcranial magnetic stimulation study of corticospinal excitability during the observation of meaningless, goaldirected, and social behaviour. Neuroscience Letters, DOI:10.1016/j.neulet.2010.11.067

Efron, B. (1979). Bootstrap methods: another look at the jackknife. Annals of Statistics, 7, 1 - 26.

Fadiga, L., Buccino, G., Craighero, L., Fogassi, L., Gallese, V., Pavesi, G. (1999). Corticospinal excitability is specifically modulated by motor imagery: a magnetic stimulation study. Neuropsychologia, 37(2), 147 - 158.

Fadiga, L., Fogassi, L., Pavesi, G., \& Rizzolatti, G. (1995). Motor facilitation during action observation: a magnetic stimulation study. Journal of Neurophysiology, 73(6), $2608-2611$.

Goodman, N. (1976). Languages of Art. An approach to a theory of symbols. Hackett Publishing: Indianopolois/Cambridge.

Grosbras, M. H., \& Paus, T. (2006). Brain networks involved in viewing angry hands or faces. Cerebral Cortex, 16, 1087 - 1096.

Grosbras M. H., Beaton, S., \& Eickhoff, S. B. (in press). Brain regions involved in human movement perception: a quantitative voxel-based meta-analysis. Human Brain Mapping.

Grèzes, J., Pichon, S., \& de Gelder, B. (2007). Perceiving fear in dynamic body expressions. Neuroimage, 35, $959-967$.

Hammond, H. (2005). Cecchetti, Carabosse and The Sleeping Beauty. Selected papers from 'An International Celebration of Enrico Cechetti' - A Society for Dance Research online publication, 2007, pp. 10-19. Presented at the Conference at University of Chichester, $31^{\text {st }}$ July 2005. URL retrieved 21st June 2011: http://www.dancebooks.co.uk/sdr-uk/docs/2005_cecchetti_conference_proceedings.pdf.

Hess, C. W., Mills, K. R., Murray, N. M. (1987). Responses in small hand muscles from magnetic stimulation of the human brain. The Journal of Physiology, 388, 397 - 419.

Hesse, M. D., Sparing, R., \& Fink, G. R. (2008). End or means - the „what“ and „how“ of observed intentional actions. Journal of Cognitive Neuroscience, 21 (4), 776-790.

Jackson, J. (submitted). Invisible leaps: women dancing into maturity. Woman and Performance. 
Jola, C., Abedian-Amiri, A. A., Kuppuswamy, A., Pollick, F. E., \& Grosbras, (submitted). Enhanced motor cortex excitability induced by watching dance in empathic and visually experienced dance spectators.

Jola, C., Ehrenberg, S., Reynolds, D. (2011). The experience of watching dance: phenomenologicalneuroscience duets. Phenomenology and the Cognitive Sciences, DOI: 10.1007/s11097-0109191-X.

Keysers, C., \& Gazzola, V. (2006). Towards a unifying neural theory of social cognition. Progress in Brain Research, 156, 379-401.

Keysers, C., \& Gazzola, V. (2009). Expanding the mirror: vicarious activity for actions, emotions, and sensations. Curr Opin Neurobiol, 19, $666-671$.

Knutson, K. M., McClellan, E. M., Grafman, J. (2008). Observing social gestures: an fMRI study, Experimental Brain Research, 188, 187 - 198.

Lagerlof, I. \& Djerf, M. (2009). Children's Understanding of Emotion in Dance European Journal of Developmental Psychology, Volume, 6(4), 409 - 431.

Lycouris, S. (2008). Hybrid Compositional Systems. Dance Improvisation. Presentation at the Dance, Timing and musical gesture conference by the Institute for Music in Human and Social Development (IMHSD), $13^{\text {th }}-15^{\text {th }}$ June, University of Edinburgh, UK.

McDonnell, M. N., \& Ridding, M.C. (2006). Transient motor evoked potential suppression following a complex sensorimotor task. Clinical Neurophysiology, 117, 1266 - 1272.

Orgs, G., Dombrowski, J.-H., Heil, M., \& Jansen-Osmann, P. (2008). Expertise in dance modulates alpha/beta event-related desynchronization during action observation. European Journal of Neuroscience, 27, $3380-3384$.

Phelan, P. (1993). Unmarked: The politics of performance. Routledge: London/NY

Pascual-Leone, A., Davey, N., Rothwell, J., Wasserman, E., \& Puri, B. K. (2002). Handbook of transcranial magnetic stimulation. Oxford University Press: London.

Pollick, F. E., Jola, C., Petrini, K., McKay, L. S., McAleer, Ph., Jang, S. H., MacLeod, Chr., \& Simmons, D. (2011). Experience and the perception of biological motion. In K. L., Johnson, \& M. Shiffrar (Eds). Perception of the human body in motion: findings, theory, and practice. Oxford University Press. In print.

Pollick, F. E., Paterson, H. M., Bruderlin, A., \& Sanford, A. J. (2001). Perceiving affect from arm movement. Cognition, 82 , B51 - 61 .

Preston-Dunlop, V. \& Sanchez-Colberg, A. (2010). Dance and the Performative, a choreological perspective - Laban and beyond. Alton: Dance Books Ltd.

Reason, M. (2010a) Watching dance, drawing the experience and visual knowledge. Forum for Modern Language Studies, 46(4), $391-414$. 
Reason, M. (2010b). Asking the Audience: Audience Research and the Experience of Theatre. About Performance. 10. 15-34.

Reason, M., \& Reynolds, M. (2010). Kinesthesia, empathy, and related pleasures: An inquiry into audience experiences of watching dance. Dance Research Journal, 42(2) 49 -75

Reboul, A. (1995). Expression: Feelings, Art and Cognition. Colloque international "Cognition et création", Albi, $12^{\text {th }}-14^{\text {th }}$ January. Online publication: halshs-00003842, version 1 , http://halshs.archives-ouvertes.fr/docs/00/02/91/05/PDF/albi.pdf, 28.12.2010.

Siebner, H. R., \& Ziemann, U. (2007). Das TM- Buch. Transkranielle Magentstimulation. Springer: Heidelberg.

Strafella, A. P., \& Paus, T. (2000). Modulation of cortical excitability during action observation: a transcranial magnetic stimulation study. NeuroReport, 11, $2289-2292$.

Stevens,C., \& McKechnie, S. (2005). Thinking in action: thought made visible in contemporary dance. Cognitive Processing, 6(4), 243 - 252.

Schmidt, S., Cichy, R. M., Kraft, A., Brocke, J., Irlbacher, K., \& Brandt, S. A. (2009). An initial transient-state and reliable measures of corticospinal excitability in TMS studies. Clinial Neurophysiology, 120, $987-993$.

Vogt, S., Buccino, G., Wohlschlager, A. M., Canessa, N., Shah, N. J., Zilles, K., et al. (2007). Prefrontal involvement in imitation learning of hand actions: effects of practice and expertise. NeuroImage, 37, 1371-1383.

Wassermann, E., Epstein, Ch., \& Ziemann, U. (2008). Oxford Handbook of Transcranial Stimulation. Oxford University Press: Oxford.

Wildschut, E.M.M. (2010). Becoming one body. In R Naber, B Nieuwboer \& L Wildschut (Eds.), Danswetenschap in Nederland. Deel 6 (pp. 75-81). Amsterdam: Vereniging voor Dansonderzoek. 


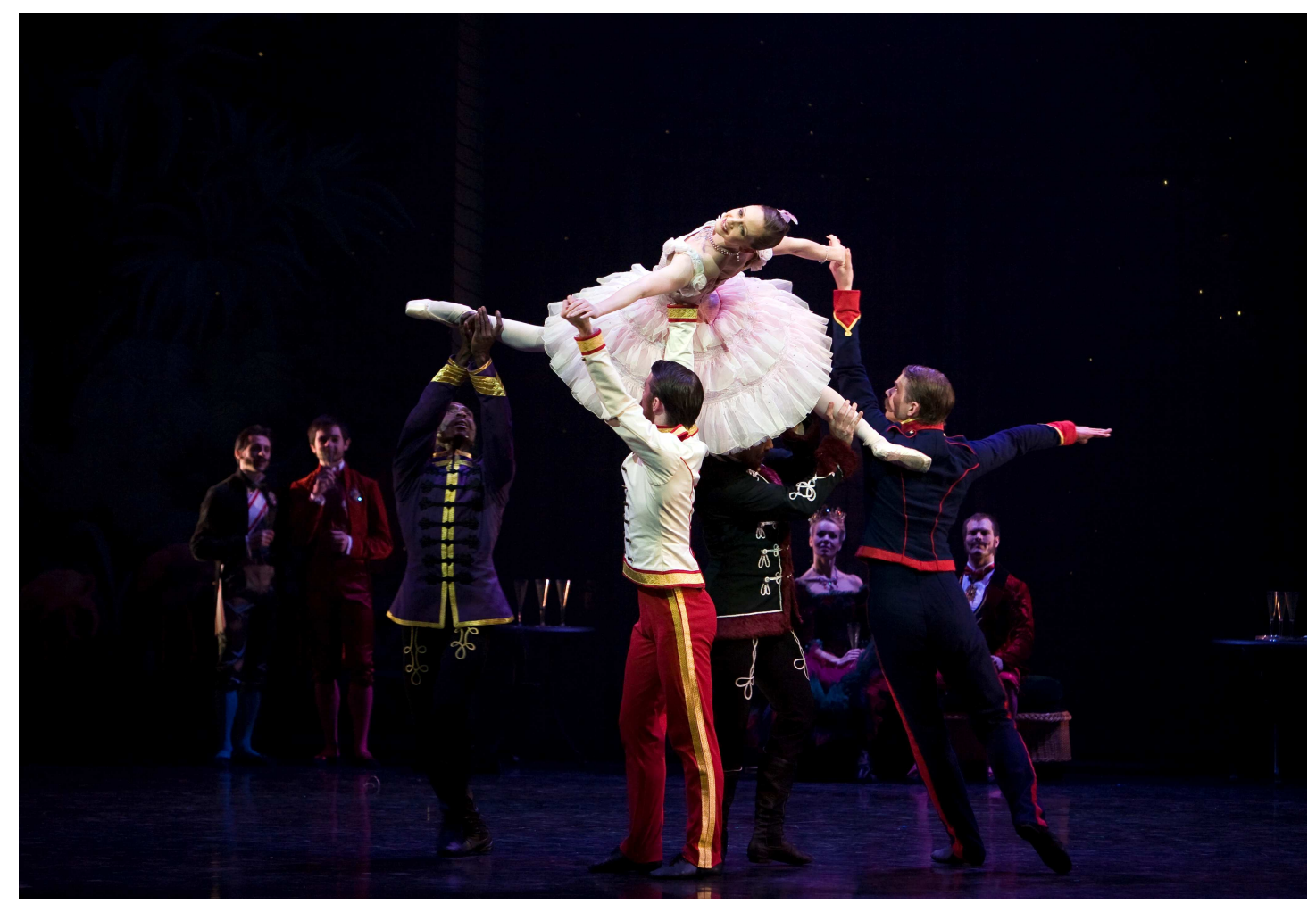

Figure 1. Still from the Sleeping Beauty live performance of Scottish Ballet. Paul Liburd as the Romanian Prince, Christopher Harrison as the Austrian Prince, Claire Robertson as Aurora, Tama Barry as the Russian Prince and Gregory Dean as the French Prince in Ashley Page's The Sleeping Beauty. Photograph by Andrew Ross. 


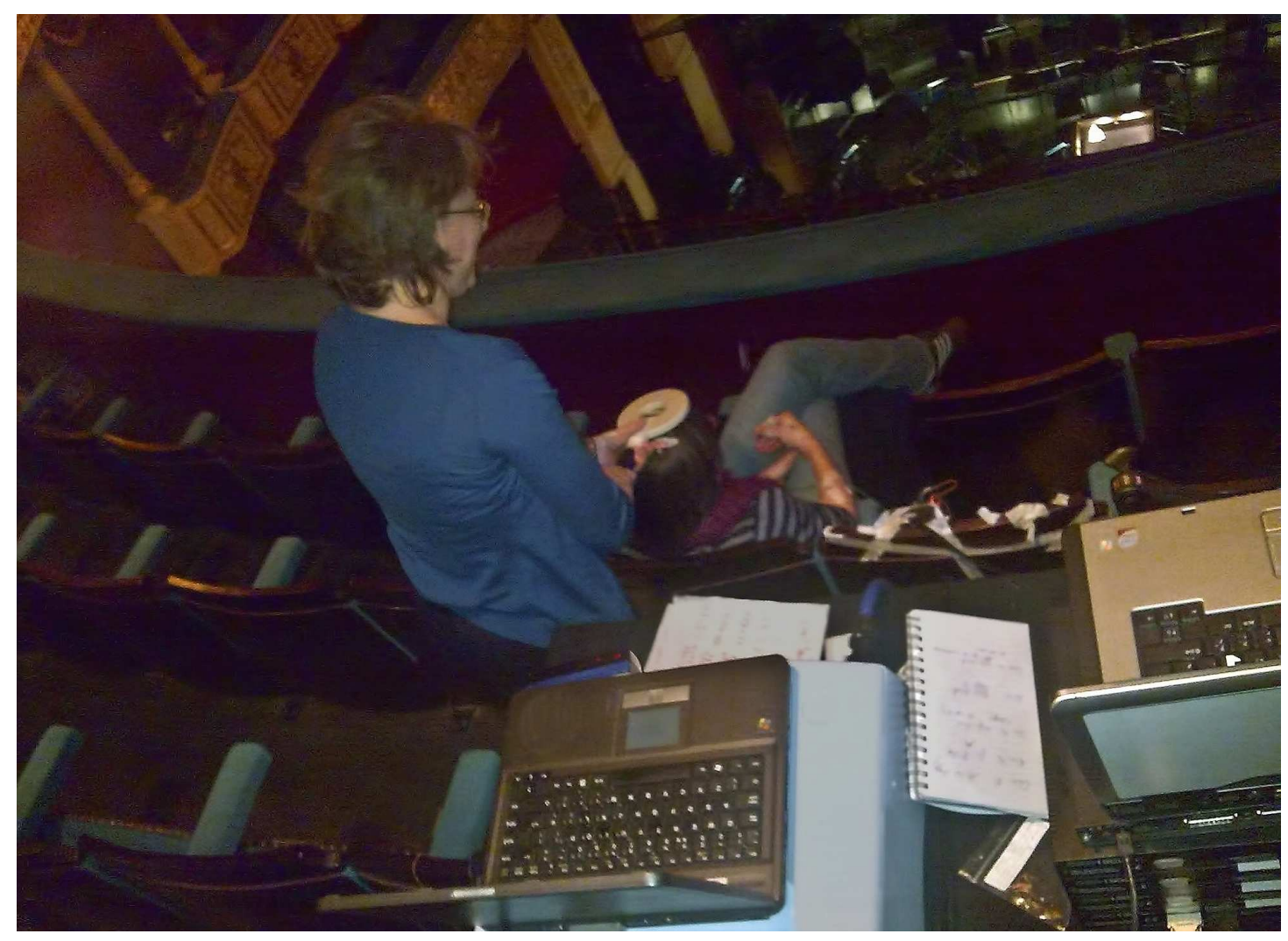

Figure 2. Technical equipment and testing environment. Shows the experimenter holding the circular headcoil (that applies the magnetic stimulation), the spectator (sitting), two laptops (experimental program and data saving), magnet stimulator and amplifier. 


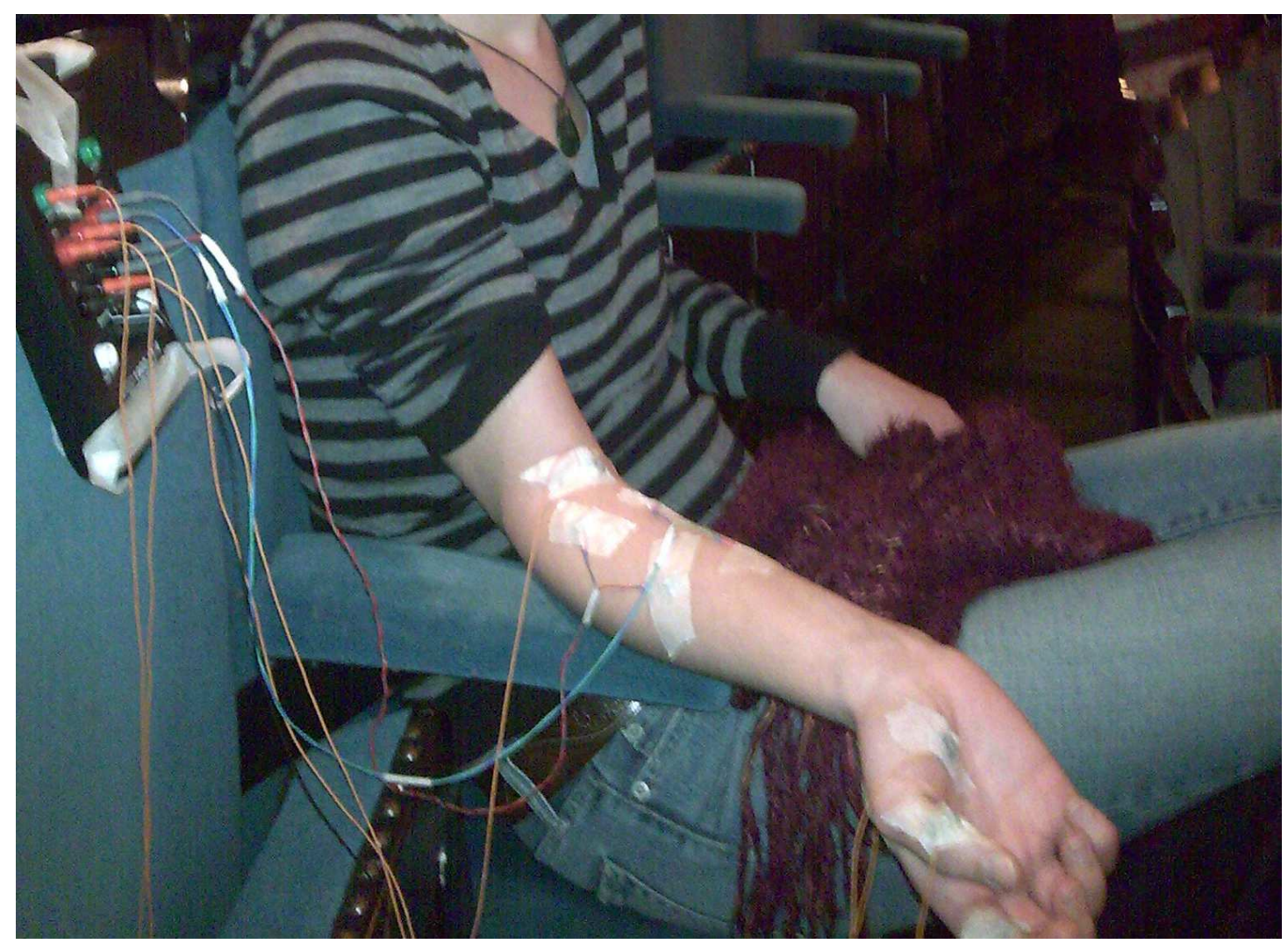

Figure 3. Electrodes application. Thenar (not analysed due to technical error), FDI, Flexor, Extensor, Reference Electrode. 

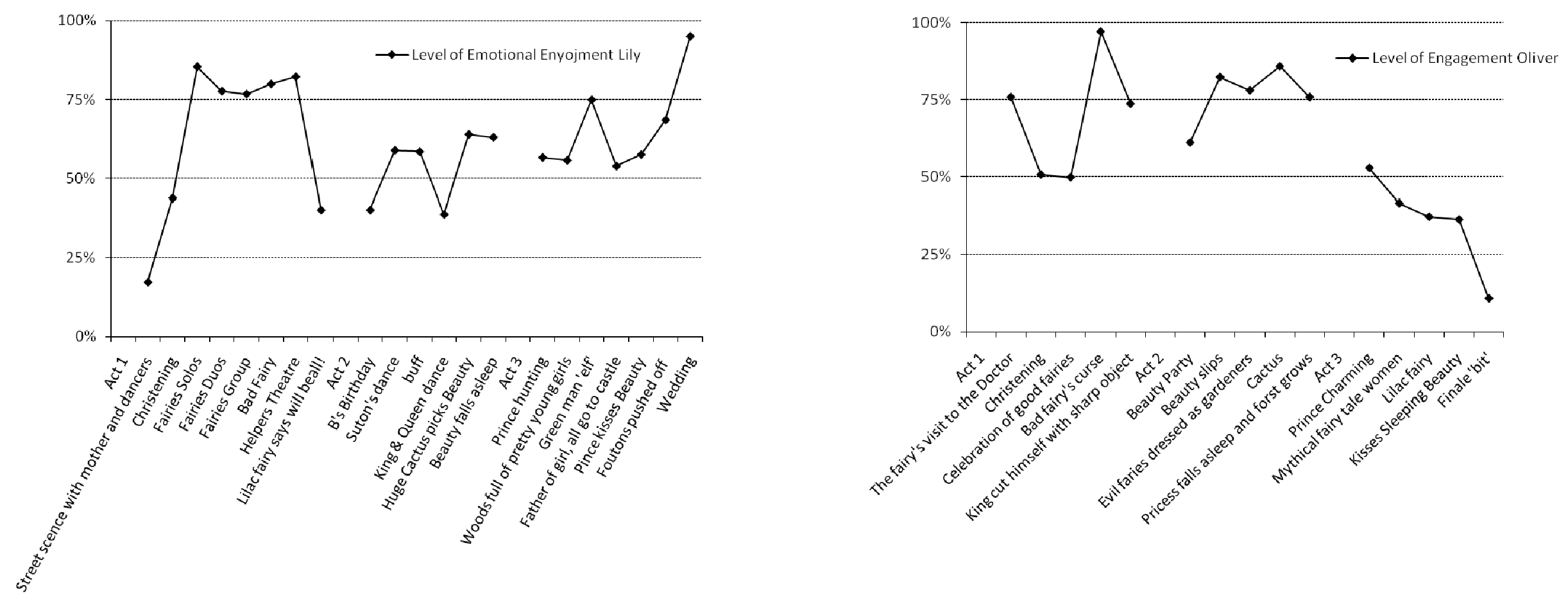

Figure 4: Changes in motor-cortical excitability of four spectators (Alexander, Oliver, Lily, Jack) by means of motor evoked potentials (MEPs) evoked by transcranial magnetic stimulation (TMS) of three muscle groups FDI (upper row), Flexor (middle row), and Extensor (lower row). Each act is presented in a different colour with decreasing intensity for the time from the start of the act. y-axis: average MEP area as percentage changes to the rest condition. x-axis: TMS bundles in different acts for different events. Flexor in Act 1 for Alexander is missing due to technical error. For demonstration purposes, values higher than $200 \%$ are indicated by the absolute value on top of the column. 


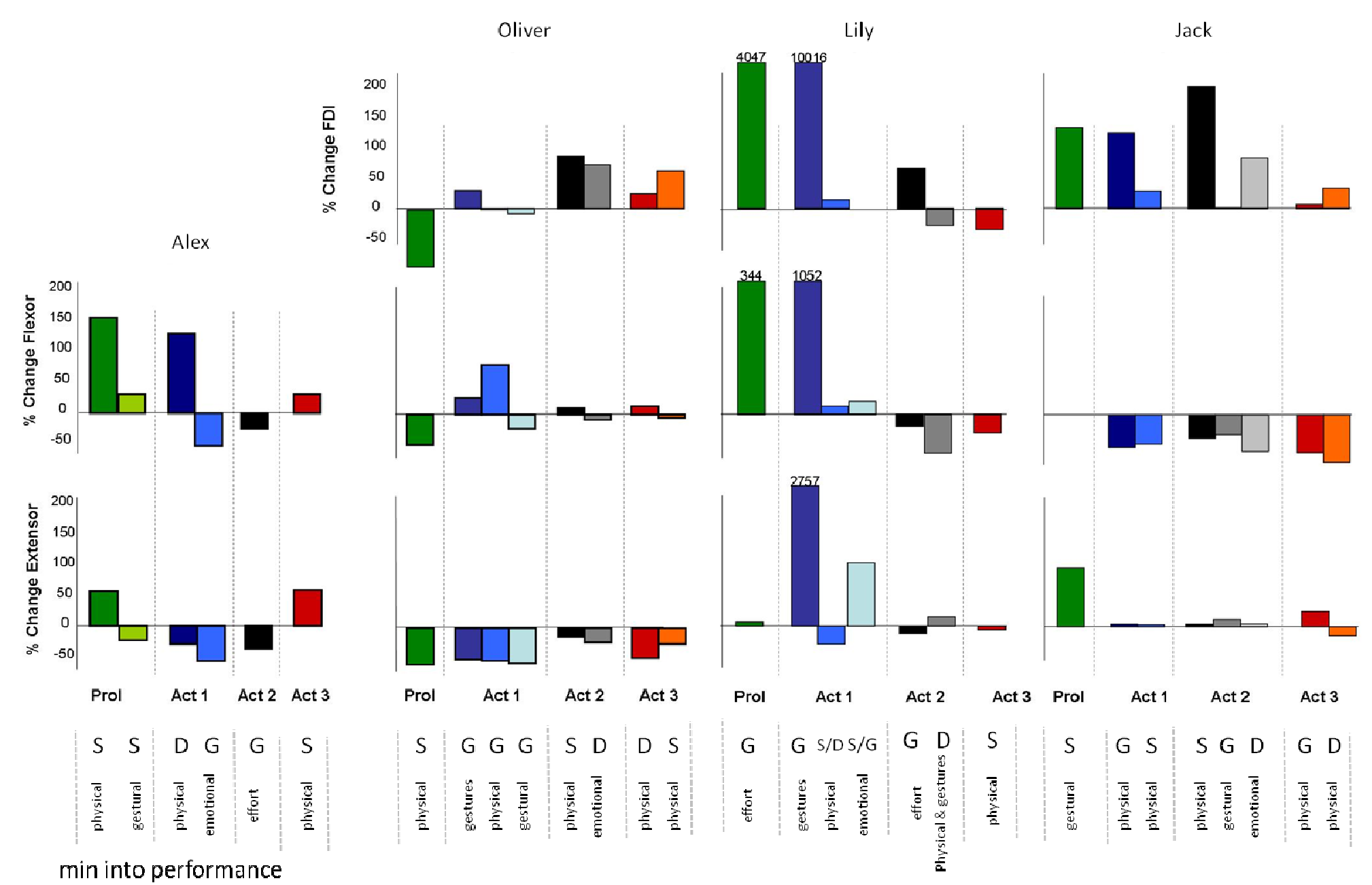

Figure 5: Qualitative responses of Lily and Oliver. Notably, the structure of the acts was remembered incorrectly by both spectators. Direct comparison of qualitative responses with TMS trigger is not possible as more events were remembered retrospectively than TMS triggers were applied. 

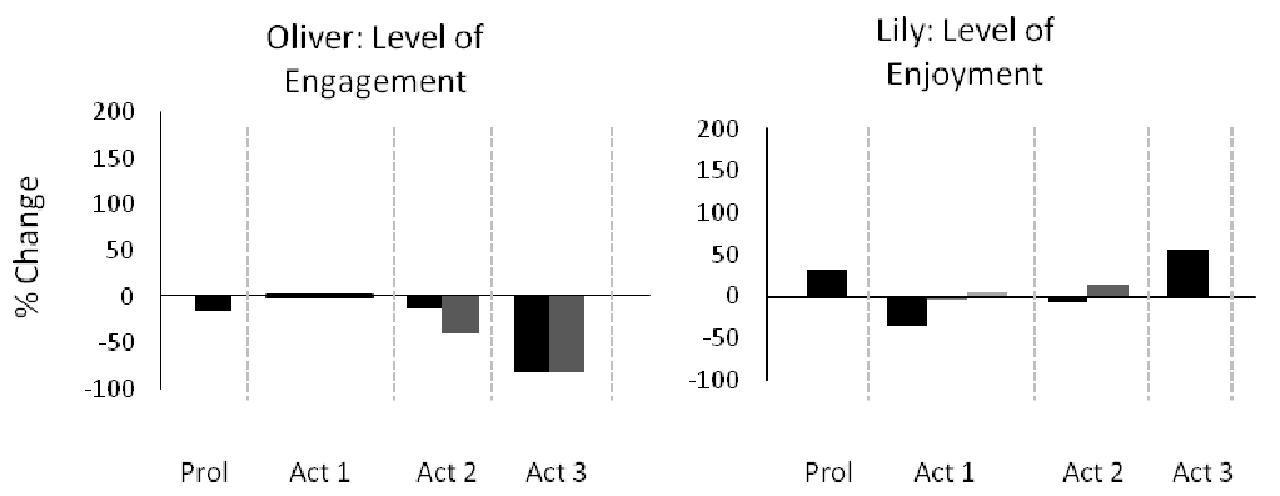

Figure 6: Qualitative responses of Lily and Oliver for those events that lay within the frames of TMS application. 